\title{
New Elastomers Based on Uralkyd/Polystyrene Interpenetrating Polymer Networks
}

\author{
Vilas AthaWALE ${ }^{\dagger}$ and Sachin Raut \\ Department of Chemistry, University of Mumbai, \\ Vidyayanagari, Mumbai 400 098, India
}

(Received April 20, 1998)

\begin{abstract}
Isocyanate terminated uralkyd resin was synthesized in the laboratory. The uralkyd resin was reacted with styrene monomer using benzoyl peroxide as the initiator and interpenetrating polymer networks (IPNs) were synthesized. The elastomers obtained showed decreasing tensile strength and hardness, whereas an increasing elongation was observed, with increase in the uralkyd content in uralkyd/polystyrene IPNs. Thermogravimetric analyses were used to study the thermal behavior of IPNs and determination of activation energy. The syntheses of the IPNs (25/75 uralkyd/polystyrene ratio) incorporating triethanolamine as a chain extender and curing agent for uralkyd resin, showed an activation energy of $19.15 \mathrm{kcal} \mathrm{mol}^{-1}$ as compared to $10.19 \mathrm{kcal} \mathrm{mol}^{-1}$ for IPNs without triethanolamine, which is nearly twice as much. No noticeable change was observed in the glass transition temperatures $\left(T_{\mathrm{g}} \mathrm{s}\right)$ of the IPNs with or without triethanolamine.

KEY WORDS Interpenetrating Polymer Networks / Uralkyd Resin / Polystyrene / Triethanolamine /
\end{abstract}

An interpenetrating polymer network (IPN) is a combination of two polymers in network form, at least one of which is synthesized and/or crosslinked in the immediate presence of the other. The multipolymer system thus obtained displays a broad range of properties, from toughened elastomers to high-impact plastics. IPNs generally possess enhanced physical properties compared to normal polyblends of their components. IPNs are polymer alloys and considered the fastest growing parts of polymer blends during the last two decades. A wealth of literature ${ }^{1-8}$ is available on oil based polyurethane and sequential or simultaneous interpenetration with vinyl monomers to get polymers of desirable properties. However, no work is reported on the synthesis and characterization of interpenetrating polymer networks (IPNs) based on uralkyd resins till today. Cured uralkyd resin is elastomeric in nature, whereas polystyrene is generally used as high impact plastic. Therefore we found it worthwhile to undertake a comprehensive study on IPNs based on uralkyd resin and polystyrene and, to study further changes in their physico mechanical properties by combining both the polymers in varying proportions. The effects of addition of triethanolamine which acts as a chain extender as well as curing agent for uralkyd resin, on the physical and mechanical properties of the IPNs have not been studied. In the present study, samples of IPNs containing different percentages of uralkyd resin and polystyrene were synthesized and their properties with and without triethanolamine were evaluated.

\section{EXPERIMENTAL}

\section{Materials \\ Refined soybean oil was obtained from Mahendra Oil Mill (Mumbai, India) and used without further purification. Pentaerythritol and phthalic anhydride (minimum assay 99.5\%) were purchased from Manali Chemicals (Mumbai, India) and s.d.fine-chem. Ltd.}

\footnotetext{
$\dagger$ To whom all correspondence should be addressed.
}

(Mumbai, India), respectively. Hexamethylene diisocyanate (HDI) was procured from Fluka (Switzerland), triethanolamine from Loba Chemie (Mumbai, India), and benzoyl peroxide from E. Merck (India). Catalyst Fascat 4100 was purchased from the local market. Divinyl benzene (E. Merck, India) and styrene (Fluka, Switzerland) were freed from stabilizer, initially by washing with aqueous $\mathrm{NaOH}(0.5 \%)$ followed by washing with water. Vinyl monomers were dried over anhydrous sodium sulfate and distilled under reduced pressure, prior to use. All other reagents were of analytical grade and used without further purification.

\section{Synthesis of Hydroxyl Terminated Soybean Oil Alkyd Resin}

A resin kettle equipped with thermometer, reflux condenser, stirrer, and nitrogen inlet was charged with one equivalent of soybean oil, two equivalents of pentaerythritol and Fascat 4100 catalyst $(0.05 \% \mathrm{w} / \mathrm{w}$ based on oil). The temperature was raised to $200^{\circ} \mathrm{C}$ and maintained till monoglyceride is formed. The formation of the monoglyceride was judged by cooling the sample to room temperature and testing its solubility in methanol. A clear and homogenous solution was obtained when the resin and pure methanol were taken at a ratio of $1: 3$ indicating the formation of the monoglyceride. The temperature was then brought down to $160-170^{\circ} \mathrm{C}$. 0.5 equivalents of phthalic anhydride were added to the reaction mixture and the temperature was slowly raised to $220^{\circ} \mathrm{C}$, at which it was maintained until acid value $<5 \mathrm{mg}$ of $\mathrm{KOH} \mathrm{g}^{-1}$ of sample, was obtained. Traces of water in the resin were removed by adding a little xylene to the reaction kettle and distilling it under vacuum. The obtained soybean oil alkyd resin, had a hydroxyl value and acid value of $155 \mathrm{mg}$ of $\mathrm{KOH} \mathrm{g}^{-1}$ of resin and $4.0 \mathrm{mg}$ of $\mathrm{KOH} \mathrm{g}^{-1}$ of resin, respectively. ${ }^{9}$

\section{Synthesis of Uralkyd Network}

A reaction kettle equipped with a thermometer, stirrer, reflux condenser and a nitrogen inlet was charged with one equivalent of $50 \%$ solution of soybean oil alkyd resin 
<smiles>O=C(F)OCC1COC(=O)OCC(F)(F)O1</smiles>

OIL<smiles>OCC(CO)(CO)CO</smiles>

PENTAERYTHRTTO<smiles>C1CC1</smiles>

MONOGLYCERTDE

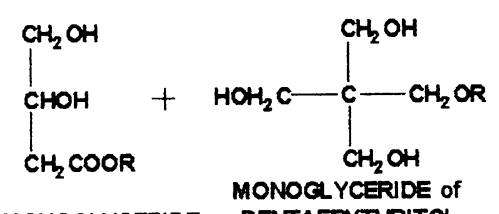

MONOGLYCERIDE OF

PENTAERTTHITOL

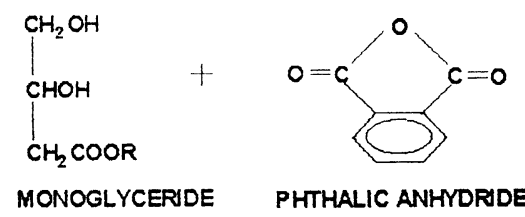

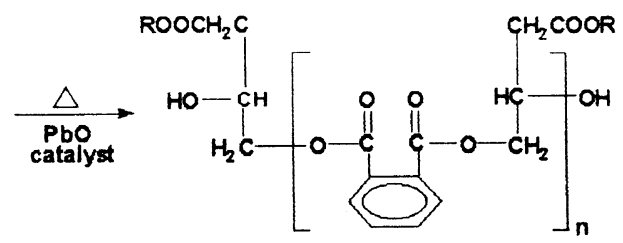

ALKYD RESIN

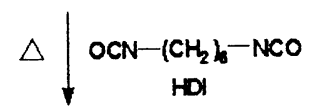

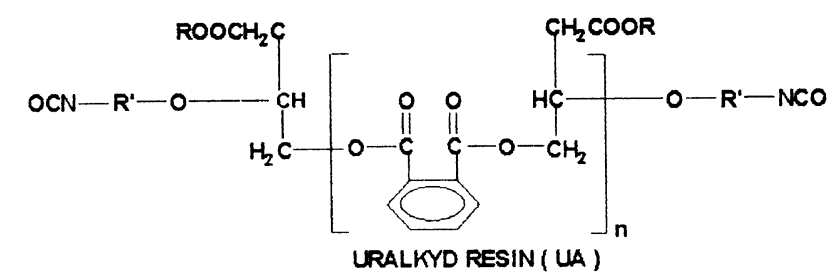

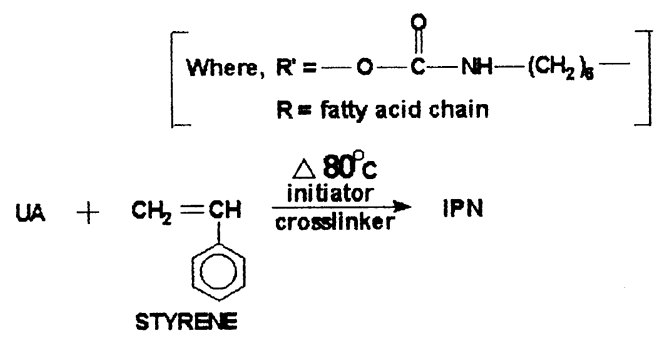

Figure 1. Scheme for the synthesis of uralkyd resin and IPN.

in toluene, followed by the addition of two equivalents of HDI. The system was placed in a thermostated water bath maintained at $40 \pm 2^{\circ} \mathrm{C}$, with continuous stirring for $2 \mathrm{~h}$. To facilitate crosslinking and chain extention, after completion of $2 \mathrm{~h}$, triethanolamine $(1 \% \mathrm{w} / \mathrm{w}$ based on the total charge) was added and thoroughly mixed for $5 \mathrm{~min}$. The resulting mixture was poured into a mold, where it was kept initially at $80^{\circ} \mathrm{C}$ for $24 \mathrm{~h}$ and subsequently at $120^{\circ} \mathrm{C}$ for $6 \mathrm{~h}$.

\section{Interpenetrating Polymer Networks (IPNs)}

IPNs were synthesized sequentially using various proportions of uralkyd resin and styrene. Uralkyd resin and styrene along with benzoyl peroxide initiator $(0.5 \%$ $\mathrm{w} / \mathrm{w}$ based on styrene) and divinyl benzene crosslinker $(1 \% \mathrm{w} / \mathrm{w}$ based on styrene) were added to the reaction kettle and were intimately mixed for $3 \mathrm{~min}$ at $40^{\circ} \mathrm{C}$. The temperature was raised to $80^{\circ} \mathrm{C}$ and the reaction was continued for $1 \mathrm{~h}$. The reaction mixture was then poured into the mold and kept in an air circulated oven, initially at $80^{\circ} \mathrm{C}$ for $24 \mathrm{~h}$ and finally at $120^{\circ} \mathrm{C}$ for $6 \mathrm{~h}$ to ensure complete crosslinking and polymerization. Amber coloured films of the IPNs were obtained. The scheme for the formation of uralkyd resin and synthesis of IPNs with polystyrene is shown in Figure 1.

\section{Characterizations}

Infrared spectra of the IPNs and the homopolymers were obtained on Shimadzu FT-IR 4200 series spectrophotometer using $\mathrm{KBr}$ pellets. Tensile strength and elongation were measured using computerized tensile testing machine "Tensilon" (R \& D Electronics, India) as per ASTM D 638, and hardness was determined with Shore A durometer using ASTM D 2240-75 standard. The apparent density of the films was obtained by weighing strips of the film of measured volume. ${ }^{10} \mathrm{~A}$ swelling study was carried out in water, methyl ethyl ketone (MEK) and toluene. ${ }^{11}$ Thermogravimetric measurements were made on a Mettler TA 4000 (TG-50) thermogravimetric analyzer (TGA) at a heating rate of $10^{\circ} \mathrm{Cmin}^{-1}$ in nitrogen atmosphere and energy of activation was computed using the Broido method. ${ }^{12}$ Glass transition temperatures were determined by differential scanning calorimetry on DuPont 9900 thermal analyser at a heating rate of $10^{\circ} \mathrm{C} \mathrm{min}^{-1}$ in nitrogen atmosphere.

\section{RESULTS AND DISCUSSION}

Infrared Spectroscopy $(I R)$

IR spectra of uralkyd prepolymer showed character- 
Table I. Compositions of homopolymers and IPNs

\begin{tabular}{lcc}
\hline Sample code $^{\mathrm{a}}$ & Composition/wt $\%$ & Polymer \\
\hline UA100T & Uralkyd 100\% & Homopolymer \\
PS100 & Polystyrene 100\% & Homopolymer \\
UA25/PS75 & Uralkyd 25\%, Polystyrene 75\% & IPN \\
UA50/PS50 & Uralkyd 50\%, Polystyrene 50\% & IPN \\
UA75/PS25 & Uralkyd 75\%, Polystyrene 25\% & IPN \\
UA25/PS75T & Uralkyd 25\%, Polystyrene 75\% & IPN \\
UA50/PS50T & Uralkyd 50\%, Polystyrene 50\% & IPN \\
UA75/PS25T & Uralkyd 75\%, Polystyrene 25\% & IPN \\
\hline
\end{tabular}

a Sample codes containing " $T$ " indicate presence of triethanolamine.

Table II. Swelling of homopolymers and IPNs

\begin{tabular}{|c|c|c|c|c|}
\hline \multirow{2}{*}{ Sample code } & \multicolumn{2}{|c|}{ Composition UA/PS } & \multicolumn{2}{|c|}{ Swelling/\% } \\
\hline & $w t \%$ & Toluene & MEK & Water \\
\hline UA100T & $100 / 0$ & 60 & 58 & 1 \\
\hline UA25/PS75 & $25 / 75$ & 200 & 99 & No change \\
\hline UA $50 / P S 50$ & $50 / 50$ & 107 & 81 & No change \\
\hline UA75/PS25 & $75 / 25$ & 81 & 68 & No change \\
\hline PS100 & $0 / 100$ & 1030 & 900 & 1.09 \\
\hline UA25/PS75T & $25 / 75$ & 229 & 122 & 1 \\
\hline UA50/PS50T & $50 / 50$ & 136 & 102 & No change \\
\hline UA75/PS25T & $75 / 25$ & 93 & 87 & No change \\
\hline
\end{tabular}

istic absorption bands at $1740 \mathrm{~cm}^{-1}$ and $3400 \mathrm{~cm}^{-1}$ corresponding to urethane and amide II (-NH stretching), respectively. As the prepolymer was isocyanate terminated, an intense and sharp band due to $\mathrm{NCO}$ was observed at $2270 \mathrm{~cm}^{-1}$. IR spectra of IPNs showed all the bands corresponding to urethane and styrene network and no additional bands thereby ruling out the possibility of chemical interaction between component networks.

\section{Swelling Study}

Swelling studies were carried out by the procedure of Sperling and Mihalakis ${ }^{11}$ and the percentage of swelling was calculated for each IPN as,

Swelling $(\%)=$

(Weight of swollen polymer - Weight of dry polymer)

$$
\text { Weight of dry polymer }
$$

$\times 100$

Swelling (\%) data of the IPNs in toluene, MEK and water are presented in the Table II. Since the entire material was crosslinked, the IPNs did not dissolve in any solvent. Swelling was more prominent in toluene and MEK, whereas no swelling was observed in water. It is evident from the table that the IPNs with triethanolamine showed greater swellability than those without triethanolamine. A perusal of the table also revealed that swelling was more prominent in toluene than in MEK. This is attributed to the low polarity of toluene. The uralkyd homopolymer showed least swelling than its IPNs and also, as the percentage of uralkyd resin increased in the IPNs, the extent of swelling decreased.

\section{Mechanical Properties}

The effects of the variation in the blend ratio on the
Table III. Mechanical properties of homopolymers and IPNs

\begin{tabular}{|c|c|c|c|c|c|}
\hline \multirow{2}{*}{$\begin{array}{l}\text { Sample } \\
\text { code }\end{array}$} & \multirow{2}{*}{$\begin{array}{c}\begin{array}{c}\text { Composition } \\
\text { UA/PS }\end{array} \\
\frac{w t \%}{} \%\end{array}$} & \multirow{2}{*}{$\begin{array}{l}\text { Tensile } \\
\text { strength } \\
\mathrm{MPa}\end{array}$} & \multirow{2}{*}{\multicolumn{2}{|c|}{$\frac{\begin{array}{c}\text { Elongation Hardness } \\
\text { shore } A\end{array}}{}$}} & \multirow{2}{*}{$\begin{array}{l}\begin{array}{c}\text { Apparen } \\
\text { density }\end{array} \\
\mathrm{g} \mathrm{cm}^{-3}\end{array}$} \\
\hline & & & & & \\
\hline UA100T & $100 / 0$ & 0.92 & 88 & 69 & 1.201 \\
\hline UA25/PS75 & $25 / 75$ & 1.68 & 26 & 93 & 1.083 \\
\hline UA50/PS50 & $50 / 50$ & 0.84 & 73 & 90 & 1.086 \\
\hline UA75/PS25 & $75 / 25$ & 0.63 & 118 & 71 & 1.091 \\
\hline PS 100 & $0 / 100$ & 42.0 & 2 & Hard & 1.050 \\
\hline UA25/PS75T & $25 / 75$ & 2.01 & 38 & 94 & 1.126 \\
\hline UA $50 /$ PS50T & $50 / 50$ & 1.11 & 90 & 91 & 1.150 \\
\hline UA75/PS25T & $75 / 25$ & 1.01 & 135 & 72 & 1.193 \\
\hline
\end{tabular}

tensile strength, percentage elongation and hardness (shore $A$ ) are presented in Table III. The elongation and tensile strength showed systematic variation with respect to the blend ratio. It is apparent from the table that, as the percentage of uralkyd resin in the blend increased, tensile strength decreased and percentage elongation increased. IPNs UA50/PS50 and UA50/PS50T showed excellent tensile strength, elongation, and hardness. IPN specimens with triethanolamine, for all the ratios, showed higher tensile strength than the corresponding IPNspecimens without triethanolamine. This can be attributed to the good interpenetration and hence greater compatibility between the two constituent polymers, in IPNs with triethanolamine as compared to those without triethanolamine. As the proportion of uralkyd resin in the blend increased the elongation increased, because, hard polystyrene was substituted more and more by uralkyd resin which is more soft and flexible. This was confirmed, as a perusal of the table revealed that, the hardness of the IPNs went on decreasing with increasing uralkyd content in uralkyd/polystyrene (UA/PS) IPNs. The presence or absence of triethanolamine had no noticeable effect on the hardness of IPNs.

\section{Glass Transition Temperatures $\left(T_{\mathrm{g}} \mathrm{s}\right)$}

The temperature was scanned from -50 to $150^{\circ} \mathrm{C}$ at a heating rate of $10^{\circ} \mathrm{C} \mathrm{min}^{-1}$ in nitrogen atmosphere. $T_{\mathrm{g}}$ of the representative IPNs lay between those of their constituent homopolymers, and although two different polymer components were used, only a single $T_{\mathrm{g}}$ was obtained, which unambiguously ruled out the possibility of any phase separation. $T_{\mathrm{g}}$ of the uralkyd homopolymer, polystyrene homopolymer, ${ }^{13}$ UA25/PS75 (without triethanolamine) and UA25/PS75T (with triethanolamine) are $25.2,100.0,61.7$, and $58.3^{\circ} \mathrm{C}$ respectively. Normal DSC curves of uralkyd homopolymer, UA25/PS75 and UA25/PS75T are shown in Figure 2. The DSC curves showed no noticeable change in $T_{\mathrm{g}} \mathrm{s}$ of the representative IPNs with or without triethanolamine.

\section{Apparent Density}

The experimental densities of the IPNs and the homopolymers are listed in Table III. The density of the uralkyd homopolymer was higher than that of the polystyrene homopolymer. Hence, as the proportion of uralkyd homopolymer increased in the blend, the density increased, since more and more polystyrene was substituted by denser uralkyd resin. In the case of the IPNs containing triethanolamine, density was higher 


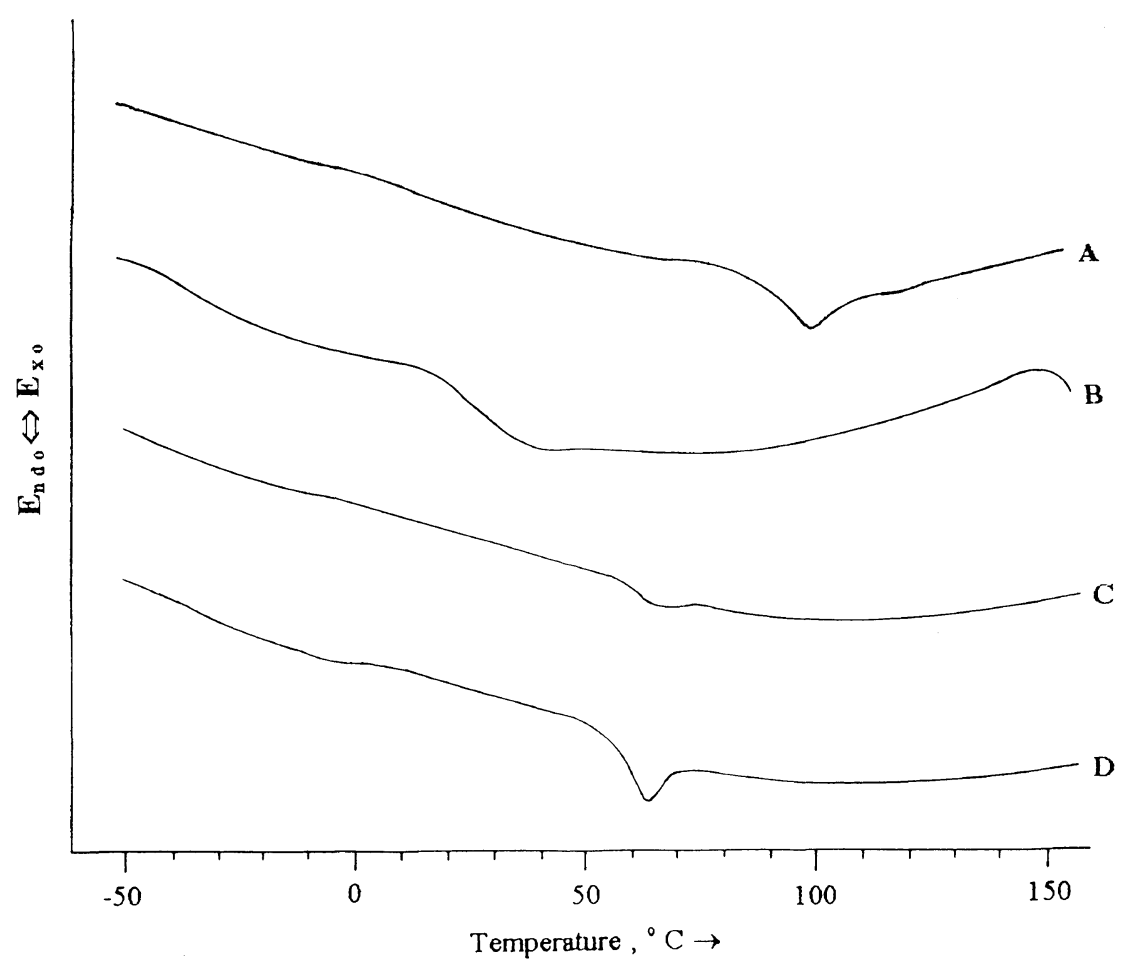

Figure 2. DSC curves of homopolymer and representative IPNs. (A) PS100; (B) UA100T; (C) UA25/PS75T; (D) UA25/PS75.

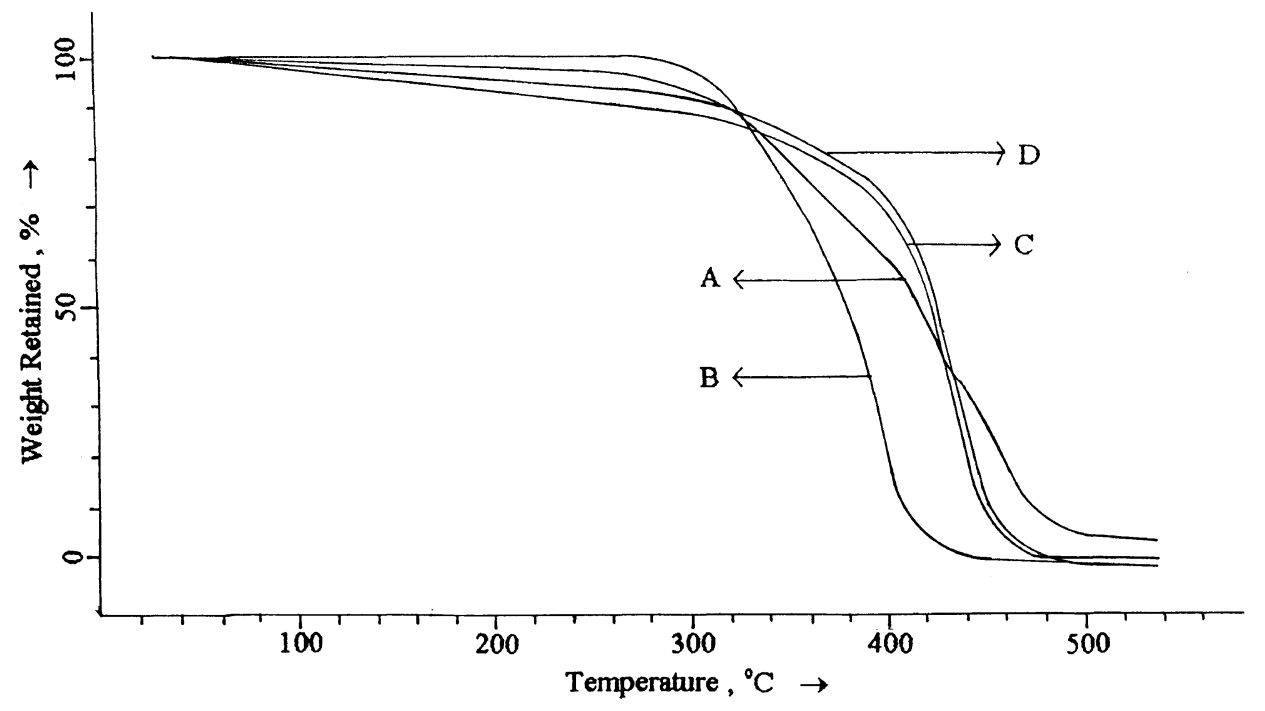

Figure 3. TG curves of homopolymers and representative IPNs. (A) UA100T; (B) PS100; (C) UA25/PS75; (D) UA25/PS75T.

than those without triethanolamine, which also gave an indication that the compatibility and extent of interpenetration between the two constituent polymers were higher in the case of the IPNs with triethanolamine compared to ones without triethanolamine.

\section{Thermal Properties}

Thermal properties of the homopolymers and the IPNs suggest that, the thermal stability of the IPNs falls intermediate between those of polystyrene and uralkyd. Clustering of the TGA curves (Figure 3) of the representative IPNs indicated that there was no significant difference in degradation behavior with or without triethanolamine. The representative IPNs showed a single stage thermal decomposition. The polystyrene homopolymer also showed a single stage thermal decomposi- tion which indicated that the unzipping of the styrene monomer took place. However, the uralkyd homopolymer exhibited three-stage thermal degradation. Stage I corresponds to the urethane bond breaking, between $200-380^{\circ} \mathrm{C}$. Stage II is the polyol decomposition stage, at $384-435^{\circ} \mathrm{C} .{ }^{14}$ Stage III indicates the complete decrosslinking and thermal degradation of the IPNs. It is clear from the activation energy $\left(E^{*}\right)$ data, Table IV that the activation energies of the IPNs were lower than their constituent homopolymers. The activation energy of the IPNs with triethanolamine was almost double of that of the IPNs without triethanolamine, since with the addition of triethanolamine the extent of crosslinking increases, thereby yielding a densely crosslinked network. This densely crosslinked network was naturally highly thermally stable compared to the 
Table IV. Thermal decomposition of homopolymers and IPNs

\begin{tabular}{|c|c|c|c|c|c|c|}
\hline \multirow[b]{2}{*}{ Sample code } & \multicolumn{3}{|c|}{ Decomposition stages } & \multicolumn{3}{|c|}{ Activation energy } \\
\hline & Stage I & Stage II & Stage III & \multicolumn{3}{|c|}{$\mathrm{kcal} \mathrm{mol}^{-1}$} \\
\hline UA100T & $200-384^{\circ} \mathrm{C}$ & $384-435^{\circ} \mathrm{C}$ & $435-532^{\circ} \mathrm{C}$ & 37.52 & 51.61 & 89.19 \\
\hline PS100 & $275-450^{\circ} \mathrm{C}$ & - & - & 36.15 & - & - \\
\hline UA25/PS75T & $43-491^{\circ} \mathrm{C}$ & - & - & 19.15 & - & - \\
\hline UA25/PS75 & $32-488^{\circ} \mathrm{C}$ & - & - & 10.19 & - & - \\
\hline
\end{tabular}

one without triethanolamine, hence an extra amount of activation energy was required by this network over that of IPN without triethanolamine. In the case of uralkyd homopolymer, the energy of activation increased from the first to third stages of decomposition, implying a corresponding increase in thermal stability at each stage.

\section{CONCLUSIONS}

The chain extention caused increase in the swellability in the IPNs with triethanolamine as compared to the ones without triethanolamine. There was increase in the density of the IPNs with increase in the uralkyd content. This effect was more pronounced in IPNs with triethanolamine compared to those without triethanolamine. The chain extention caused by triethanolamine significantly increased the thermal stability of the IPNs. The soybean oil based uralkyd resin elastomer was soft and flexible. IPNs based on uralkyd resin and polystyrene as the plastic component were quite clear as well as tough. Hence depending upon the composition of the two polymers, tough plastics and reinforced elastomers can be obtained that meet specific use requirements.

\section{REFERENCES}

1. G. M. Jenwo, J. A. Manson, J. Pulido, L. H. Sperling, A. Conde, and N. Devia, J. Appl. Polym. Sci., 21, 1531 (1977).

2. L. H. Sperling, "Interpenetrating Polymer Networks and Related Materials," Plenum Press, New York, N.Y., 1981.

3. M. Patel and B. Suthar, J. Polym. Sci., Polym. Chem. Ed., 25, 2251 (1987).

4. P. Patel and B. Suthar, Polymer, 31, 339 (1990).

5. P. L. Nayak, S. Lenka, S. K. Panda, and T. Patnaik, J. Appl. Polym. Sci., 47, 1089 (1993).

6. Chakrabarty and B. Das, J. Appl. Polym. Sci., 60, 2125 (1996).

7. P. Nayak, D. K. Mishra, D. Parida, K. C. Sahoo, M. Nanda, S. Lenka, and P. Nayak, J. Appl. Polym. Sci., 63, 671 (1997).

8. V. Athawale and S. Kolekar, Eur. Polym. J., in press.

9. A. O. C. S. Official Method, 1989 , Cd $4-40$ (1989).

10. H. L. Frisch and D. Klempner, Polym. Lett., 7, 775 (1969).

11. L. H. Sperling and E. N. Mihalakis, J. Appl. Polym. Sci., 17, 3811 (1973).

12. A. Broido, J. Polym. Sci., Polym. Phys. Ed., 7, 1761 (1969).

13. J. Bandrup and E. H. Immergut., "Polymer Handbook," 3rd ed, John Wiley and Sons, New York, N.Y., 1989, V/82-85.

14. P. D. Nair and M. Jayabalan, J. Polym. Sci., Polym. Chem. Ed., 28, 3775 (1990). 